\title{
BREVE MANIFIESTO SOBRE EL ESTADO CONSTITUCIONAL
}

Raúl Gustavo Ferreyra*

\section{APERTURA}

Antes de ahora, he emprendido una investigación y una reflexión sobre el Estado constitucional en América del Sur. Quizás exista una "matemática del espíritu, cuyas leyes terribles no son tan inviolables como las que rigen las combinaciones de los números y de las líneas"1. Aunque el Derecho que emerge de las constituciones, ciertamente, no habita en la precisión de ninguna de las matemáticas ni en las espirituales ni en las no espirituales.

La tarea, por tanto, ha sido terminada, con madurez creciente e imperfecciones fruto genuino de la ambigüedad, policromía y vaguedad del Derecho, que se transmite al Derecho constitucional. El texto se encuentra en prensa y será publicado en 2015 y llevará por título Manifiesto sobre el Estado constitucional. Raíces y razones de la mancomunidad estatal. Una pieza extensa, de más de 150 páginas.

Dado el homenaje que me brinda el Centro de Ensino Superior de São Gotardo, Estado de Minas Gerais, República Federativa del Brasil, he decidido adelantar estas letras que componen la Lectio, en señal de fraterna colaboración científica. Juzgo interesante adelantar las ideas de la contribución indicada en el párrafo anterior; especialmente "ajustadas" para esta eminente ocasión, aun a sabiendas de que se corra algún riesgo, quizá por no estar en el marco del texto completo. Entonces llamo a esta contribución "Breve...", que incluye, naturalmente, las ideaciones principales recogidas en la versión in extenso. No pretendo su "soberanía"; me contentaré con una adecuada "autonomía". Por razones de espacio y para empalmar con la orientación sugerida para la edición de este homenaje, prescindiré de la mención y descripción de normas en

\footnotetext{
* Lectio doctoralis pronunciada el 21 de noviembre de 2014 con motivo de la recepción del doctorado Honoris Causa por el Centro de Ensino Superior de São Gotardo, Minas Gerais, Brasil. La laudatio fue compuesta por el Prof. Dr. Paulo Bonavides; no pudo concurrir por razones de salud y fue leída en su representación por el Prof. Dr. Paulo Lupo Saraiva. El Centro de Ensino Superior de São Gotardo fue representado por su rector, João Eduardo Lopes Queiroz.

** Catedrático de Derecho constitucional, Facultad de Derecho, Universidad de Buenos Aires, Argentina. E-mail: rgferreyra@hotmail.com.ar
}

1 ARLT, Roberto. Los siete locos. Buenos Aires: Planeta, 2013. p. 73. 
la argumentación. En el mismo sentido, también se despeja el camino de citas doctrinarias y jurisprudenciales, en todo cuanto fuese posible.

\section{AFIRMACIÓN CAPITAL}

La tesis pura de este "Breve manifiesto" es la siguiente: llámase "Estado constitucional" a todo ente que congrega en su composición dos elementos constituyentes naturales (territorio y población) y dos elementos constituyentes no naturales (poder y constitución); uno de estos últimos es el "artificio fundamental", la suma regla suprema del orden estatal, cuya estabilidad y perdurabilidad se intenta establecer con hegemonía suficiente. En el Estado constitucional todo el Derecho del Estado debe ser Derecho genuinamente autorizado por la norma positiva fundamental de su orden coactivo.

El ámbito de reflexión y de escritura se encuentra en la Argentina y dentro del marco de ordenación prescrito por el sistema de su "Constitución federal", pero con vocación para desarrollar, genuinamente, inferencias que, más temprano que tarde, sean susceptibles de tipificar aspectos sobre la "identidad" del constitucionalismo en América del Sur. La concepción de la constitución como cuarto elemento del Estado significa un "programa", aunque su comprensión teórica y su consecuente concreción empírica, en este momento, no se orienten de modo directo hacia una laboriosa edificación de una "identidad constitucional sudamericana", cuyo peso relevante o criterio rector residiese, eventualmente, en el discurso público originado por el Derecho de la constitución.

\section{LA CONSTITUCIÓN, CUARTO ELEMENTO DEL ESTADO}

La constitución no es un ente mundano aislado. Puede aislarse para su estudio dogmático; es decir, comprender, desde una perspectiva interna, su entidad y describir sus propiedades. Sin embargo, ella desempeña su tarea, con mayor o menor eficacia, con mayores o menos logros, dentro del ente estatal. Por consiguiente, también existe un enfoque externo: el propio modo en que la constitución se da, se presenta, se relaciona, en fin, reglamenta y fundamenta al mundo de los elementos del Estado; o el Estado a secas. Porque construir constitucionalmente al Estado no es tarea sencilla. Por eso, las orientaciones conceptuales sobre "organizarlo u ordenarlo" -siempre con rol fundamental- no son una

2 Peter Häberle, en 1982, anunció su tesis, pieza a pieza, en Verfassungslehre als Kulturwissenschaft ("la Constitución como cultura"), Berlín. La tesis se reitera en "La constitución en el contexto", Anuario Iberoamericano de Justicia Constitucional (AIJC), CEPC, Madrid, $\mathrm{n}^{\circ}$ 7, 2003, pp. 223-225). Adviértase: en este escrito se resuelve deslizar a la constitución como un "cuarto elemento"; simplemente, sin ahondar en la inherente proyección "cultural" de la tesis del profesor alemán para nuestro "contexto" sudamericano. 
mera cuestión de fe o de vocabulario: siempre se encuentran abiertas a delimitación y discusión crítica.

Los elementos del Estado siguen siendo el territorio, la población y el poder; sin embargo, tratándose de la arquitectura del poder y el deslinde entre autoridad y ciudadanía, con semejante sustantividad, la constitución se incorpora como cuarto y nuevo elemento al sistema. La concepción de la constitución como cuarto elemento significa un programa que se presenta -en la Argentina y, eventualmente, para América del Sur en pos de un nuevo modelo de integración real- y se intenta desarrollar paso a paso, porque no pretende privar de "fuerza expresiva” a la elemental trilogía de constituyentes del Estado ${ }^{3}$.

En particular, el Estado argentino se encuentra fundamentado constitucionalmente por la suma regla más antigua de las sudamericanas que gozan de vigencia. Al igual que todos los Estados de América del Sur, la Argentina "ordena" su vida "estatal" por intermedio de una constitución. En el caso de la Argentina, el artificio fue inventado en 1853 e impuesto desde entonces. La Constitución nació a mediados del siglo XIX en el marco de un débil, fragmentado y casi inexistente contractualismo comunitario; sin embargo, transcurridos más de 160 años, sus determinaciones abstractas, abiertas y concisas, amén de sus reformas, la han convertido en un bien comunitario indispensable (mejor dicho: "un bien jurídico de naturaleza colectiva"4) para que cada individuo puede diseñar el plan de vida que le plazca y desarrollarlo, reformarlo, con total libertad, sin interferencias. En principio, no existe otro "Estado" que no se encuentre "constituido" por la respectiva "constitución”. ¡No debería existir vida estatal fuera de la "constitución”, pero existe! Aunque también se yergue un derecho estatal fuera de la constitución, aquí no hay espacio para su detallado tratamiento ${ }^{5}$.

\section{LAS REGLAS CONSTITUCIONALES}

Elegir al artificio constitucional como fundamento del Estado constituye una determinación política. Se adopta con antelación a la arquitectura estatal y se funde con sus fines. Por dicha razón, al desenvolverse la elección señalada se "opera" entre la decisión política y la propia arquitectura del sistema "una relación circular" que rige "toda la construcción" futura 6 .

3 HÄBERLE, Peter. La constitución en el contexto. Madrid: AIJC, CEPC, 2003. Nº 7, p. 225. 4 BIDART CAMPOS, Germán J. La constitución que dura (1853-2003 - 1994-2004). Buenos Aires: Ediar, 2004. p. 22.

5 Para la evaluación de esta cuestión, se remite a FERREYRA, Raúl Gustavo. La constitución vulnerable. Crisis argentina y tensión interpretativa. Buenos Aires: Hammurabi, 2003. y también al ensayo "¿Tiempo constitucional? La constitución vulnerable". Disponible en: $<$ www.infojus.gov.ar>

6 ZAFFARONI, E. Raúl; ALAGIA, Alejandro; SLOKAR, Alejandro. Derecho penal. Buenos Aires: Ediar, 2000. p. 104-105. 
"Fundamento" se utiliza en varios sentidos y en múltiples contextos. Por amor a la claridad conceptual, entre la variopinta gama de significados, indico, a continuación, los elegidos. Así, "fundamento" en tanto "raíz" y "fundamento" en tanto "razón" son los senderos escogidos, en coincidencia con algunas de las alternativas lexicográficas. "Fundamentos constitucionales", en referencia a su raíz, porque toda la construcción jurídica de una comunidad, en determinado tiempo y espacio, queda o debe quedar sustentada, soportada, en fin, "fundamentada" por el propio Derecho que emana de la constitución, o cuya validación ésta autoriza. "Fundamentos constitucionales", en referencia a su razón, porque la validez jurídica de todo el Derecho de una comunidad, en determinado tiempo y espacio, queda o debe quedar explicada, justificada, en fin, "fundamentada" por el propio Derecho que emana de la constitución, o cuya validación ésta autoriza.

La fundamentación constitucional del Estado se cumple o puede cumplirse por intermedio de cuatro principios o reglas: subordinación, variación, distinción y acción. Ninguna de estas reglas o principios posee una realización absoluta; por eso son reglas "inacabadas" o reglas de realización progresiva, o reglas de realización relativa. Además, se asume en este texto que no existen diferencias ontológicas o estructurales entre los principios y las reglas que emanan de las normas constitucionales; las desemejanzas entre las unas y los otros son más bien de estilo, pese a que desde el punto de vista de la literatura jurídica, en general, se prefiere "regla". Bien entendido: que en toda obra literaria son esenciales el estilo y las ideas ${ }^{7}$.

Entonces, estos cuatro principios o reglas que emanan de la constitución pueden ser descritos como de terminación inacabada, porque por su intermedio se pretende fundamentar la regulación del Estado o la limitación de su inherente poder. En su etapa de fundamentación estatal cada uno de estos principios o reglas constitucionales se desenvuelve activamente, ya sea para configurar una raíz, o ya sea para justificar una razón. Son "materiales estructurales", "pilares", o mejor, "elementos de la arquitectura del interior del Estado" emplazados positivamente, puestos en la constitución. Sin embargo, para mantener incólume el rigor analítico, se prefiere agruparlos en dos órdenes, exactamente parejos a los “fundamentos constitucionales". Más específicamente, pues, la regla sobre la variación o cambio y la regla

\footnotetext{
7 No asumo la distinción fuerte y débil, respectivamente, entre principios y reglas. Nótese: no significa que la distinción no posea entero fundamento; simplemente, es preciso señalar que tiene un alcance y contenido explicativo bastante más reducido del que comúnmente se le asocia, dado que la mayor parte de los principios, tendencialmente, se comportan como las reglas, porque también son "Derecho sobre Derecho", portadores de sana normatividad. Se sigue, en general, la consistente tesis de Luigi Ferrajoli, expuesta en "Constitucionalismo principialista y constitucionalismo garantista", en Un debate sobre el constitucionalismo, Marcial Pons, Madrid, 2012, pp. 11-50, 2012.
} 
sobre la subordinación caen dentro del marco de los fundamentos constitucionales, observados como raíz. En cambio, la regla sobre la distinción y la regla sobre la acción se corresponden, o mejor dicho, son la manifestación de los fundamentos constitucionales, apreciados, en este caso, como razón o justificación para el ejercicio de la fuerza estatal. Estos principios o reglas que surgen constitucionalmente observan el siguiente contenido.

\subsection{Primera regla: sobre la subordinación}

Una de las definiciones fijadas por el Diccionario de la Real Academia Española sobre "subordinación" - "Sujeción a la orden, mando o dominio de alguien"- deja constancia semántica precisa de cuanto se discute. En efecto, en el "Estado constitucional", la subordinación del ente a la ordenación fundamental determinada por la constitución liga con decisión intransigente el propio concepto de Estado.

La regla sobre la subordinación jurídica del Estado por intermedio de cada uno de los despliegues que la constitución dispone (supremacía normativa; relación con el Derecho internacional de los Derechos Humanos -DIDH-; control de constitucionalidad y rigurosa juridicidad) persigue establecer la certeza, es decir, el "conocimiento seguro" por parte de la ciudadanía y los servidores públicos sobre la determinación del campo dominado por el Derecho y del otro campo libre, un mundo sin reglas jurídicas.

Los ciudadanos y los servidores públicos deben realizar el Derecho de la constitución.

La normatividad de los desarrollos de cada uno de los despliegues de la regla sobre la subordinación del Estado al Derecho constitucional debería hallarse, en general, fuera de discusión. No corresponde juzgar a la regla ni a sus despliegues específicos como mera exhortación ni baños de moralidad. Con los alcances de sus prescripciones jurídicas, inevitablemente, hacen presuponer o representar que la certeza en el mundo estatal - pasado, presente y sobre todo porvenir- queda afianzada, se encuentra ligada, en fin, subordinada a una regla artificial: la constitución, que no tiene nada de orden metafísico. La certeza siempre es "...certeza de alguien respecto de algo"8; en nuestro caso, nada más y nada menos que del hombre sobre el orden jurídico que fundamenta al Estado.

\subsection{Segunda regla: sobre la variación}

La constitución contiene una certidumbre: que su escritura

8 BUNGE, Mario A. Diccionario de Filosofía, "Certeza", México: Siglo Veintiuno, 2001. p. 213-214. 
metódica sólo podrá ser expandida, contraída o revisada, por el propio proceso detallado en su texto. Autoriza un solo lenguaje posible, por intermedio de un modelo autorreferente. El propio proceso de su cambio formaliza, sin temores, que la constitución puede ser reformada, con el debido respeto de sus determinaciones precisas, que nunca pueden ser entendidas como epístolas inútiles. De este modo, el artificio constitucional arraiga y afianza la estructura del Estado, al permitir el cambio de la regla suprema, que no es la copia ni imitación de ningún ente $\mathrm{u}$ objeto perfecto e ideal. Por eso corresponde habilitar la propia metamorfosis de la constitución. Me refiero al proceso real que cada orden jurídico regula y establece con sus propios matices, pero que en todos ellos participan los ciudadanos al elegir sus representantes y, en modo eventual, aprobar las normas elaboradas por el órgano constituyente, como así también la determinación de los órganos constitucionales y constituyentes determinados, de manera respectiva, para proceder a la variación normativa. Justificadamente, pues, la reforma configura un fundamento notable que sustenta la certeza en la edificación continua del orden jurídico del Estado.

La constitución es una entidad mundana; no debe ser ídolo de ilustración ni ser juzgada como el producto inalcanzable de personas sabias o no sabias, que en su mayoría han muerto. No obstante, cualquier variación debe seguir, detalladamente, el protocolo establecido en la propia letra constitucional. Fuera de la canalización dispuesta en la constitución, no hay cambio autorizado. La autoridad creada por la constitución no debe disponer cambios fuera del proceso político y jurídico prescrito en la suma regla. El cambio es una posibilidad enorme en la vida de los hombres. Arraigar, entonces, el cambio constitucional a un proceso clave e indisponible consagrado, en modo autorreferente, también confiere certeza en las relaciones humanas.

\subsection{Tercera regla: sobre la distinción de funciones}

Para construir un edificio es necesario que un arquitecto diseñe los planos; luego, que los obreros y los técnicos se ocupen materialmente de la edificación. Para escribir una novela o un mero relato resulta menester conocer la gramática o tener presente, acaso, que quienes lean el texto deben compartir el código escrito por el autor. Para construir y mantener jurídicamente a esa personalidad colectiva que se apoda "Estado", inevitablemente, unos hombres tendrán que dar órdenes, encontrarse facultados para mandar con atribuciones suficientes, y otros deberán obedecerlas, ya sea por leal convicción, o por otro motivo que influya y determine el estado de dominación. El poder es el primer elemento no natural del Estado. Poder entendido como competencia atribuida a órganos del Estado en los que reside la capacidad para 
mandar o la facultad para dar órdenes, generar permisos o instalar prohibiciones. El poder es una cuestión fundamental en el Derecho de la constitución que ordena al Estado, con otra orientación, desde luego, pero con igual importancia que la libertad, que es la otra cuestión o materia fundamental.

La división de los poderes estatales tiene por inocultable finalidad contribuir a la consecución de lo que cotidianamente parece imposible, o digno de una de las más fantásticas de las utopías: someter el poder al cumplimiento de reglas de juego jurídicas preestablecidas. Se trata de impedir la concentración de los poderes. El fraccionamiento del poder del Estado constituye un formidable escudo de protección para la libertad de los habitantes.

En términos constitucionales, el poder se distingue en "constituyente" y "constituidos": Derecho constituyente y Derecho constituido. La constitución es producida y concretada en los "momentos constituyentes"; el resto de las reglas jurídicas de alcance general son creadas por el Congreso federal o el departamento ejecutivo; excepcionalmente, por el poder judicial.

La división horizontal del poder tiene lugar en la casa republicana: departamentos precisos que se encargan de la producción o realización del Derecho. La atribución de competencias comporta la existencia de zonas de reserva o, mejor dicho, potestades específicamente descritas, que no deben ni pueden ser invadidas por otro órgano, so pena de sanción. Ciertamente: existen ámbitos de competencias concurrentes, por ejemplo la formación de la ley, que es un acto entre el órgano Congreso y el órgano ejecutivo; pero, aun en dicho caso, cada órgano tiene una competencia propiamente asignada e indelegable. Todos los Estados de América del Sur adoptan el modelo republicano, sin equivocaciones. En el caso de la Argentina, se trata de un modelo tripartito, con un órgano extrapoder -el ministerio público- desde 1994.

La división vertical del poder tiene lugar ya sea por la vía del federalismo o del unitarismo; Brasil y la Argentina, por ejemplo, son modelos auténticamente federales, si acaso nos guiamos por la letra constitucional. En la Argentina, el grado de descentralización alcanza al Estado federal, también a 24 entes federados y, luego, a los municipios.

La división del poder, en el Estado constitucional, constituye la regla organizativa fundamental. Al mismo tiempo, se ha observado que si la premisa antropológica es la "dignidad humana", su consecuencia organizativa debe ser la democracia. Desde que no existe democracia sin división del poder, entonces, la vinculación es evidente. En los términos postulados, la regla sobre la división del poder justifica la existencia del Estado constitucional.

9 HÄBERLE, Peter. El Estado constitucional. México: UNAM, Instituto de Investigaciones Jurídicas, 2003. p. 193. 


\subsection{Cuarta regla: sobre la acción. Derechos fundamentales}

Hay constituciones que, en tanto fundamento de "soporte" y de "validez" de los sistemas jurídicos, no se limitan a programar un conjunto de procedimientos dirigidos a posibilitar la planificación y despliegue de la coerción a cargo de los poderes constituidos. Además, y aceptando que ellas no son fines sino medios, reputan que los derechos fundamentales en ellas insertados realizan una reglamentación que se considera el ámbito básico de la vida comunitaria en libertad, donde se les concibe no sólo como derechos subjetivos, sino también como reglas objetivas del sistema y, como tales, formal y no materialmente, líneas de acción que deben asegurar un uso correcto de la fuerza estatal. Esta proposición implica la comprensión global de las complejidades que muestran las realidades configuradas por esos órdenes. No apareja el abandono de la proposición que señala que la actividad dogmática jurídica consiste en describir el estado de cosas que el Derecho configura y determina. Naturalmente, esta demarcación o determinación jamás puede ser completa. Resulta casi imposible que la constitución pueda determinar todas las orientaciones de su realización. En el Estado constitucional, la eliminación radical del ámbito de la discrecionalidad es insuperable; la discrecionalidad es un rasgo dominante de la especie humana.

La Constitución federal de la Argentina, por caso (básicamente: Primera Parte, Capítulo Primero: "Declaraciones, derechos y garantías"; Capítulo Segundo: "Nuevos Derechos y Garantías", y en la Segunda Parte, Título Primero, Sección Primera, Capítulo Cuarto: "Atribuciones del Congreso", art. 75, inc. $22^{10}$ ), contiene una descripción del estado

10 Por intermedio de la reforma constitucional de 1994 se dispuso en el art. 75 , inc. 22: “... Corresponde al Congreso (...) inciso 22: Aprobar o desechar tratados concluidos con las demás naciones y con las organizaciones internacionales y los concordatos con la Santa Sede. Los tratados y concordatos tienen jerarquía superior a las leyes. La Declaración Americana de los Derechos y Deberes del Hombre; la Declaración Universal de Derechos Humanos; la Convención Americana sobre Derechos Humanos; el Pacto Internacional de Derechos Económicos, Sociales y Culturales; el Pacto Internacional de Derechos Civiles y Políticos y su Protocolo Facultativo; la Convención sobre la Prevención y la Sanción del Delito de Genocidio; la Convención Internacional sobre la Eliminación de todas las Formas de Discriminación Racial; la Convención sobre la Eliminación de todas las Formas de Discriminación contra la Mujer; la Convención contra la Tortura y otros Tratos o Penas Crueles, Inhumanos o Degradantes; la Convención sobre los Derechos del Niño; en las condiciones de su vigencia, tienen jerarquía constitucional, no derogan artículo alguno de la primera parte de esta Constitución y deben entenderse complementarios de los derechos y garantías por ella reconocidos. Sólo podrán ser denunciados, en su caso, por el Poder Ejecutivo nacional, previa aprobación de las dos terceras partes de la totalidad de los miembros de cada Cámara. Los demás tratados y convenciones sobre derechos humanos, luego de ser aprobados por el Congreso, requerirán del voto de las dos terceras partes de la totalidad de los miembros de cada Cámara para gozar de la jerarquía constitucional".

A su vez, la ley 24.820 -publicada en el Boletín Oficial del 29/5/1997- otorgó jerarquía constitucional a la Convención Interamericana sobre Desaparición Forzada de Personas, aprobada por la XXIV Asamblea General de la OEA, en los términos del art. 75, inc. 22, de 
de cosas mencionado en los apartados anteriores, es decir, un estado de cosas deseado por el legislador constituyente sobre los derechos fundamentales.

Los derechos fundamentales, pues, constituyen reglas o líneas significativas para la acción estatal y ciudadana. En el cuerpo de la Constitución federal encuentran reglamentación los siguientes: derecho a la vida, derecho de libertad, derecho de igualdad, derechos políticos, derecho de propiedad y función social, derechos sociales, derechos de incidencia colectiva y el contrato generacional ambiental; a esta composición de ocho voces se unen los "derechos no enumerados"; con igual jerarquía constitucional, al "noneto" de derechos descrito se vinculan, desde luego, los derechos cuya nomenclatura yace en los trece instrumentos que gozan de la mayor estatura jurídica en la Argentina. Unos (el "noneto" descrito en la Constitución federal) y los otros (descritos en los instrumentos internacionales sobre Derechos humanos que gozan de jerarquía constitucional, en las condiciones de su vigencia) congloban un nuevo sistema, el sistema de la Constitución federal de la Argentina. En su conjunto, intentan justificar el accionar del Estado y el de los ciudadanos entre sí.

\section{FUNDAMENTACIÓN CONSTITUCIONAL DEL ESTADO}

Uno. Los animales se encuentran en el mundo; probablemente sean "felices mientras tengan salud y suficiente comida"11. El hombre, en forma bien diferenciada y distinguida de aquéllos, pretende la comprensión y segura observación mundana. El hombre, con la guía de su razón siempre imperfecta y el respaldo en su experiencia siempre susceptible de verificación, intenta ejercer y desarrollar cierto tipo de dominio sobre el mundo para que éste sea, quizá, más acogedor y también objeto de transformación. La naturaleza, en suma, configura un mundo dado o presentado al hombre; éste, con sus invenciones científicas o tecnológicas trata, en general, de mejorar las condiciones iniciales al construir otros "mundos artificiales"12. El Estado, el Derecho y la constitución son entes artificiales; también, naturalmente, la asociación que da lugar a la mancomunidad: "Estado constitucional".

El orden natural, si acaso fuese tal, no requiere procesos de control, pero puede producir, ciertamente, situaciones de "encantamiento" al espectador o a quien realice o intente su compresión. Por el contrario,

la Constitución federal. Por su parte, la ley 25778, publicada en el BO el 3/9/2003, otorgó jerarquía constitucional a la Convención sobre la Imprescriptibilidad de los Crímenes de Guerra y de los Crímenes de Lesa Humanidad, adoptada por la Asamblea General de la ONU el 26/11/1998 y aprobada por ley 24.584.

En consecuencia, hoy trece instrumentos del DIDH gozan de jerarquía constitucional.

11 RUSSELL, Bertrand. La conquista de la felicidad. Barcelona: De Bolsillo, 2003. p. 21.

12 BUNGE, Mario. La ciencia. Su método y su filosofía. Buenos Aires: Siglo Veinte, 1977. p. 9. 
el orden social, inventado por el hombre, sí requiere procesos de control. Sin embargo, las ordenaciones fundamentales desarrolladas por los artificios para el control social creados por él no deberían producir encantamiento acrítico, porque al no ser objetos naturales siempre reflejan una serie de relaciones de fuerza, en constante cambio. Identificar la desigualdad de los hombres reviste tarea prioritaria en el examen del origen y desarrollo del Estado constitucional.

Dos. La naturaleza de la determinación fundamental sobre la construcción y arquitectura de un Estado constitucional responde a la política y a las relaciones de fuerza engendradas y que se ejercen, por eso, con suficiente hegemonía. La definición sobre la arquitectura estatal tiene carácter preliminar; dicha determinación fundamental consiste en una resolución que la comunidad de ciudadanos adopta entre la pluralidad de alternativas que en la realidad se ofrecen. La aludida determinación fundamental, construida por los ciudadanos, en la inteligencia de que el pluralismo es la propiedad indisputable y señalada de esa asociación ciudadana, plantea los objetivos, traza el programa, genera el plan y los procesos; empero, la edificación jurídica del Estado constitucional mantiene con la determinación política iniciadora una relación que rige toda la construcción, y luego de su finalización aguarda, con firmes expectativas, su dominio.

Tres. Cada Estado tiene una historia detrás y cada historia estadual es única. Para la vida de los hombres una forma de ordenación es absolutamente necesaria para el control responsable de la paz, aunque esa forma no imponga necesariamente un Estado. Aunque se ha asumido que el término "Estado" fue introducido en la literatura por Maquiavelo en el siglo XVI y que Cicerón en el siglo I antes de Cristo ya había anunciado que "la cosa pública es lo que pertenece al pueblo"13, en las líneas que anteceden la mancomunidad de individuos, cuya descripción es objeto de estudio, se corresponde con la reunión contemporánea constituida y expresada en pleno desarrollo del siglo XXI y su correspondiente gestión o realización pública.

Cuatro. Con respecto a la posición del Estado y sus elementos naturales, corresponde plantear claramente la función "escénica" que cumple el territorio. Al mismo tiempo, se adquiere un compromiso seguro con la ciudadanía real, antes que la meramente formal. Por fin, en relación con el poder, se describen sus dos presentaciones en el Estado constitucional, ora como poderes constituyentes, ora como poderes constituidos.

El artificio constitucional constituye el cuarto elemento del Estado. Se ilustra un enfoque original: la conexión de la constitución con el ente que fundamenta: el Estado. Las construcciones dogmáticas, en general, se detienen en la evaluación interna del objeto. Aquí, sin

13 CICERÓN. Obras Políticas. "Sobre la República”. Madrid: Gredos, 2009, p. 47. 
desdeñar dicha perspectiva de la constitución, se la vincula en sus tareas de fundamentación, ya sea como raíz del orden jurídico estatal, ya sea como justificación del mismo orden.

Cinco. Significativamente, el Derecho que emana de la constitución, o cuya validación ella con la más alta jerarquía promueve y protege, comprende el cuarto elemento, definido o caracterizado como fundamental del Derecho del Estado. Porque el poder, la energía para mandar y ordenar debe ser canalizada. El poder, canalizado con participación de los individuos que quedan sometidos al orden, arroja, como resultado, la constitución. La dogmática sobre el Derecho constitucional resultante no puede configurar otro estado de cosas que una teoría del Estado constitucional.

Todo el Estado se encuentra constituido por la constitución, porque ella canaliza, mejor dicho, envasa y contiene las determinaciones políticas fundamentales establecidas por los individuos que integran la comunidad estatal. Todo el Derecho del Estado debe ser Derecho autorizado por la constitución. Existe una notable excepción: ciertos aspectos de la emergencia política, económica y financiera tienden a no calzar en la constitución.

Pese a todas las ilusiones sobre la igualdad y la solidaridad, en el Estado constitucional, fundamentalmente, se comprende y experimenta la libertad. El mundo del Estado constitucional resulta el mundo de individuos que son o persiguen ser igualmente libres, porque, al fin y al cabo, la "historia del mundo es la historia de la libertad"14.

Seis. Que el Estado posea una constitución para ordenarse o darse una constitución para organizarse condensa la afirmación básica de esta lección, es decir: determinar la relación entre el ente comunitario y uno de sus constituyentes que traza y desarrolla sus "fundamentos"; dicho de otro modo: la constitución o los fundamentos constitucionales del Estado.

Siete. La constitución, al fijar determinados procedimientos singulares, cumpliría la función responsable de la más alta alcurnia, atribuible a los procesos jurídicos: alentar la paz. Precisamente, en principio en el Estado constitucional, la constitución cumple un rol eminentemente procesal, porque la tensión entre individuo y Estado, el conflicto entre ciudadano y autoridad, imposible de resolver con rasgos definitivos, se disuelve a favor de determinados procedimientos que subordinan la actuación estatal al Derecho de la constitución. También, en menor medida, cumple un rol sustantivo por intermedio de las líneas de acción contenidas en los derechos fundamentales, porque en este caso el desarrollo queda a cargo de la autoridad pública, inclinada muchas veces a invadir las zonas protegidas, en las que se encuentra obligada a abstenerse, o a mostrar inmovilidad u omisión en las zonas

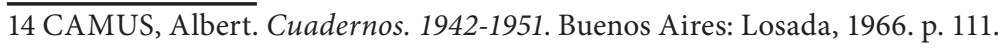


en las que se encuentra obligada a concretar prestaciones.

Una constitución que "ordena" no compromete la idea de su realización completa y perfecta. Su falta de completitud o reducción es un defecto del proceso de la realización del Derecho constitucional en el Estado. Al mismo tiempo, su progreso resulta proporcional al real desempeño de la díada "libertad ciudadana" y "poder público", siempre tensionados, por lo general, en desmedro patético de la primera.

Ocho. En el Estado ordenado u organizado con fundamentos en una constitución, su constitucionalización nunca es cabal ni totalizadora. Las reglas constitucionales que fundamentan al mencionado Estado prescriben con bastante suficiencia: la subordinación certera de su orden jurídico, la autorización detallada para su cambio formalizado, la distinción de las funciones controladas de sus poderes gubernativos y notable literatura sobre la acción de sus derechos fundamentales; baste señalar, por ahora, que la descripción constituye el resultado de una previa comprensión analítica, que guarda para cada regla un rasgo básico o manifestación preferencial de su entidad propia.

Nueve. En las secciones anteriores no se persigue un tipo ideal de estado constitucional. Se guarda la expectativa que la descripción del "modelo normativo determinado" pueda ser objeto ulterior de una ampliación y tipificación, por ejemplo en América del Sur. En este idioma: si los principios y reglas en cuestión analizados críticamente para el Estado argentino y desde el sistema de su Constitución federal son verdaderamente objetos que dan lugar a ejemplos de un tipo y todos ellos poseen, en una comprensión a realizar, en otro sitio y lugar, un cierto "aire de familia".

Diez. El poder del Estado es un poder sobre los hombres. El papel del Estado es el de proteger (y fomentar) la "riqueza total"15 (bienes más servicios) de los individuos que integran una comunidad. Desde otro ángulo, se puede proveer otra idea muy simplificada del Estado constitucional; en efecto, quizá podría ser comprendido como un enorme, un gigantesco rompecabezas, cuyos objetivos pueden ser resumidos en proteger o alentar las siguientes cuestiones: (i) la educación y la cultura, (ii) la salud, (iii) la economía y las finanzas, y (iv) la política, con apego al ambiente en que sus miembros desarrollan su vida, y también lo harán las generaciones futuras. Muchos de los arquitectos o constructores del rompecabezas han muerto. El diseño original contiene algunas líneas que hoy provocan rechazo, desdén o anomia, o emplean "un lenguaje asaz diferente del que hablamos ahora"16; otras, la mayoría, ejercen atracción porque su cotización asegura determinado espacio de libertad, cierta igualdad y una frágil e inasible solidaridad. Al mismo tiempo, el

15 BUNGE, Mario. Filosofía política. Barcelona: Gedisa, 2009. p. 333.

16 BORGES, Jorge Luis. "La Biblioteca de Babel", Ficciones. En: Obras completas. Buenos Aires: Emecé, 1974. p. 467. 
rompecabezas quiebra, daña, rompe o altera el propio concepto original de rompecabezas, porque no tiene una única ordenación de los millones de sus piezas genuinas, valiosas y originales; no hace falta decir que éstas no se encuentran numeradas, aunque, por lo general, los arquitectos que las diseñaron les atribuyeron "una desigualdad originaria". Nótese que es justicia fundamental predicar que dicha desigualdad originaria siempre careció de fundamentación racional o evidencias en su apoyo. Desigualdad entre los individuos, por lo general, atribuible al desarrollo y disfrute de todos los bienes, excepto los derechos eminentemente políticos, que gozan de cierta equidad.

Todas las piezas, por definición original, son iguales políticamente entre sí y todas desean, persiguen con presencia persistente, un sitio en el mundo o territorio del rompecabezas, porque existen otras desigualdades -apuntadas arriba- en el disfrute de otros bienes: cultura, economía y biología. En este marco territorial, el poder constitucionalmente fijado en la ley suprema debe armonizar las piezas, cada día, cada hora, cada año, luchando para conservar el ambiente, profundizar la equidad política y fomentar la eliminación de la desigualdad o alcanzar la socialización efectiva de los bienes colectivos. Escrito de este modo, sinceramente, pensar o idear que las reglas examinadas en esta pieza -cuya metáfora, parcial o totalmente, acaso pudiese ser dirigida al Estado constitucionalsolucionen el asunto requeriría no sólo de servidores públicos eficaces, sino también de "descifradores ambulantes"17 a tiempo completo, que solamente existen en la prosa de la ficción. Con más modestia, por tanto, queda para la prosa del Derecho constitucional determinar marcos para colaborar con las ilusiones sobre la esperanza de una convivencia pacífica, en la que todos los ciudadanos disfruten o puedan disfrutar del casi inalcanzable "bienestar general", en una sociedad de ciudadanos iguales no solamente en libertad. Porque, si fuese cierta la anticipación del poeta - "para todos pan [y] para todos rosas"18 (de la libertad)-, ello significa que, si unos no tienen el pan, usarán la libertad para reclamarlo y que, si en cambio sólo tienen el pan, reclamarán por su inherente libertad para controlar a quienes lo producen y lo reparten, y con seguridad se queden con la mayor parte; acaso, todo ${ }^{19}$.

El Estado constitucional, quizá, signifique una ideación infinitamente más potente que su apropiada concreción en la realidad política comunitaria. Hace años se ha dicho que una "constitución no hace en absoluto a un Estado, salvo en la más estricta significación literal, un auténtico Estado constitucional" ${ }^{20}$. En ninguna de las líneas anteriores

17 BORGES, Jorge Luis. Op. cit.

18 ÉLUARD, Paul. Obras escogidas. Buenos Aires: Editorial Platina, 1962. p. 80.

19 ZAFFARONI, E. Raúl. "Ciudadanía y jurisdicción en América Latina”. Contextos, Seminario de Derecho Público de la Defensoría del Pueblo de la Ciudad de Buenos Aires. 2012, $\mathrm{n}^{\circ} 4$, p. 27.

20 LOEWENSTEIN, Karl. Teoría de la constitución. Barcelona: Ariel, 1979. p. 161. 
apelé al juego de palabras, porque juzgo relevante la cruda descripción, sin la complaciente veneración en que incurren ciertos intérpretes que creen posible un inexistente culto oficial a la constitución, olvidando la más genuina posibilidad entregada por la "sociedad abierta ${ }^{21}$ ": o todos realizamos el Derecho constitucional, o el Derecho constitucional es simplemente una nueva forma arbitraria e irracional de dominación. Tampoco ahora jugaré con las palabras. Bastará, por eso y para finalizar, una afirmación, con igual pureza teórica que la perseguida en la sección I: sin constitución, no hay Estado constitucional, porque las cuatro reglas aquí reportadas fomentan la ilusión de que los ciudadanos sean efectivamente iguales en libertad y el poder constituido constituya una zona de competencias limitadas sometidas al control racional.

\section{REFERENCIAS BIBLIOGRÁFICAS}

ARLT, Roberto. Los siete locos. Buenos Aires: Planeta, 2013.

BIDART CAMPOS, Germán J. La constitución que dura (1853-2003 1994-2004). Buenos Aires: Ediar, 2004.

BORGES, Jorge Luis. "La Biblioteca de Babel", Ficciones. En: Obras completas. Buenos Aires: Emecé, 1974.

BUNGE, Mario A. Diccionario de Filosofía, "Certeza”, México: Siglo Veintiuno, 2001.

BUNGE, Mario. Filosofía política. Barcelona: Gedisa, 2009.

BUNGE, Mario. La ciencia. Su método y su filosofía. Buenos Aires: Siglo Veinte, 1977.

CAMUS, Albert. Cuadernos. 1942-1951. Buenos Aires: Losada, 1966. CICERÓN. Obras Políticas. "Sobre la República". Madrid: Gredos, 2009. ÉLUARD, Paul. Obras escogidas. Buenos Aires: Editorial Platina, 1962.

FERRAJOLI, Luigi. "Constitucionalismo principialista y constitucionalismo garantista”. En: Un debate sobre el constitucionalismo. Madrid: Marcial Pons, 2012.

FERREYRA, Raúl Gustavo. La constitución vulnerable. Crisis argentina y tensión interpretativa. Buenos Aires: Hammurabi, 2003.

HÄBERLE, Peter. El Estado constitucional. México: UNAM, Instituto de Investigaciones Jurídicas, 2003.

HÄBERLE, Peter. La constitución en el contexto. Madrid: AIJC, CEPC, 2003.

HÄBERLE, Peter. "La sociedad abierta delos intérpretes constitucionales: una contribución para la interpretación pluralista y 'procesal' de la Constitución”. En Academia. Revista sobre enseñanza del Derecho. 2008, año $6, n^{\circ} 11$, p. 29-61.

LOEWENSTEIN, Karl. Teoría de la constitución. Barcelona: Ariel, 1979.

21 HÄBERLE, Peter. "La sociedad abierta de los intérpretes constitucionales: una contribución para la interpretación pluralista y 'procesal' de la Constitución”. En Academia. Revista sobre enseñanza del Derecho. 2008, año 6, $\mathrm{n}^{\circ}$ 11, p. 29-61. 
RUSSELL, Bertrand. La conquista de la felicidad. Barcelona: De Bolsillo, 2003.

ZAFFARONI, E. Raúl. "Ciudadanía y jurisdicción en América Latina”. Contextos, Seminario de Derecho Público de la Defensoría del Pueblo de la Ciudad de Buenos Aires, 2012, $\mathrm{n}^{\circ} 4$.

ZAFFARONI, E. Raúl; ALAGIA, Alejandro; SLOKAR, Alejandro. Derecho penal. Buenos Aires: Ediar, 2000. 